Lexis Vol. XLV (2) 2021: 659-690

\title{
La formación del quechua ecuatoriano: una nueva hipótesis
}

\begin{abstract}
César Itier
Institut National des Langues et Civilisations Orientales (París, Francia) cesar.itier@inalco.fr
\end{abstract}

\section{RESUMEN}

Desde los estudios de Alfredo Torero, se suele considerar que el quechua ecuatoriano-colombiano procede de una variedad antiguamente hablada en la costa central del Perú e introducida en Ecuador mediante un comercio marítimo en una época anterior al imperio inca. En base a la comparación dialectal y a un examen de las fuentes históricas, refutamos esta tesis y mostramos que la variedad septentrional del quechua es el producto de una "cuzqueñización" de las hablas de los colonos norperuanos instalados por los incas en Ecuador. Este estudio de caso nos conduce a cuestionar la clasificación genética de los dialectos quechuas propuesta por Torero. Palabras claves: quechua, inca, Ecuador, dialectología

\section{The Formation of Ecuadorian Quechua: A New Hypothesis}

\section{Abstract}

Since the studies of Alfredo Torero, Ecuadorian-Colombian Quechua is often considered to come from a variety that was formerly spoken on the central coast of Peru and introduced into Ecuador through maritime trade long before the formation of the Inca empire. Based on a dialectal comparison and an examination of historical sources, we refute this thesis and 
show that Northern Quechua is the product of a strong influence of Cuzco Quechua on the speech of the North Peruvian settlers that were brought by the Incas into Ecuador. Finally, this case study leads us to question the genetic classification of Quechua dialects proposed by Torero.

Keywords: Quechua, Inca, Ecuador, dialectology

Aplicando el método comparativo a la fonología de los dialectos quechuas, Alfredo Torero sostuvo a partir de 1964 que estos se dividían en dos conjuntos — que llamó QI y QII-, los cuales se remontarían a una bifurcación dialectal primaria en la historia de la lengua. De acuerdo con esta clasificación, la variedad ecuatorianocolombiana, a la que denominó QIIB, formaría parte de la rama QII, junto con las variedades norperuanas, algunas hablas de la vertiente occidental de la sierra central peruana (Pacaraos, Laraos y Lincha) y las variedades surperuanas (el ayacuchano y el cuzqueño), con sus prolongaciones bolivianas y argentinas (Torero 2002: 74-85). Esta configuración, en que una rama dialectal, el QII, se extiende por ambos lados de la otra, el QI, planteaba a nivel histórico un reto explicativo, para el cual Alfredo Torero desarrolló una hipótesis que durante mucho tiempo suscitó un amplio consenso entre los especialistas. Él atribuyó la difusión del QII hacia el norte y hacia el sur a la acción de los mercaderes de Chincha — un valle de la costa surcentral peruana- durante los siglos que precedieron al imperio inca, en el primer caso mediante un comercio marítimo (1984; 2002: 89). Hay que reconocer que los indicios históricos y arqueológicos reunidos por Torero en apoyo a esta tesis son magros, por no decir inexistentes, y que él tampoco demostró un parentesco cercano entre las variedades de Cajamarca, Ferreñafe y Ecuador, por un lado, y las de Pacaraos, Laraos y Lincha, por otro, más allá de observaciones muy puntuales. Por otra parte, con respecto a lo que sabemos de los procesos de propagación lingüística en otras partes del mundo, la propuesta de una difusión comercial del quechua carece de plausibilidad, en particular porque ni la historia ni la arqueología atestiguan la presencia de colonias chinchanas fuera del valle de Chincha. 
La tesis de un comercio preincaico y marítimo de los chinchanos ha sido refutada por Anne-Marie Hocquenghem (2012) y por nosotros (2013). Creemos haber mostrado, además, que no existe evidencia histórica alguna de que los chinchanos, y en general los habitantes de la costa central y surcentral del Perú, fueran quechuahablantes (Itier 2013). Jorge Gómez Rendón (2017: 10) observa, por su parte, que "de haber sido la vía marítima el acceso primero del quechua hacia la zona de los Andes septentrionales, debería quedar rastro de su presencia, si no es en los registros etnohistóricos, al menos en la toponimia preinca de la costa".

La tesis del origen centro-costeño del quechua septentrional, por lo tanto, debe ser abandonada. Mostraremos aquí que dicha variedad se formó en dos etapas. La primera fue la colonización de los Andes septentrionales por los incas y sus aliados norperuanos, que dio lugar a un proceso de koinetización: variedades norperuanas del quechua se implantaron por el corredor interandino "ecuatoriano", al mismo tiempo que experimentaban una fuerte influencia del quechua cuzqueño, dando origen a un probable continuo sociolectal (o a varios continuos). La segunda etapa ocurrió con la colonización española de dicho espacio, cuyas modalidades impactaron el quechua de forma particular: el traslado masivo de la población indígena hacia la esfera económica española (haciendas, obrajes, ciudades) condujo a la extinción de las lenguas locales, habladas en las comunidades, en beneficio de un conjunto de variedades regionales del quechua, a cuya evolución morfosintáctica los hablantes criollos contribuyeron de modo muy importante, debido a la densidad de las interacciones entre indígenas y españoles dentro de las mencionadas unidades productivas.

\section{RASGOS DISTINTIVOS DEL QUECHUA ECUATORIANO-COLOMBIANO}

Desde un punto de vista genético, las hablas de Ecuador y Colombia constituyen claramente una misma rama; presentan, además, una gran unidad en cuanto a morfología y léxico, a excepción de los préstamos de lenguas de sustrato, muy variables de una región a otra. 
Este conjunto dialectal, que llamamos "quechua septentrional", se prolonga en la Amazonía peruana por las cuencas de los ríos Napo, Tigre y Pastaza. Pierde la nitidez de sus contornos en la cuenca del Pastaza peruano, donde comparte varios rasgos con el quechua de Lamas, perteneciente a la rama norperuana, junto con las variedades de Chachapoyas, Cajamarca y Ferreñafe (Taylor 1979: 10-13). No abordaré aquí la cuestión de la formación de la variedad del Pastaza peruano, que guarda relación con la antigua confluencia, en la cuenca del Marañón, de un quechua de procedencia quiteña y de una variedad de origen norperuano: el lamista. Resulta sorprendente que, pese a los trabajos de Taylor, Torero (2002: 82) siguiera agrupando el quechua ecuatoriano con el de Chachapoyas-Lamas en base a una sola innovación común: la reinterpretación de */q/ como $/ \mathrm{k} /$, es decir, la fusión de ambos fonemas en beneficio del segundo. Siendo la oclusiva uvular */q/ la más marcada de las consonantes del quechua y la que experimentó mayores variaciones fonéticas de un dialecto a otro, es altamente probable que esta innovación se produjera de modo independiente en las dos variedades, es decir, que no sea históricamente conjuntiva, como ya lo había señalado Parker en un artículo de 1970 (2013: 232).

Aparte de la velarización de */q/, las innovaciones que definen el quechua septentrional con respecto a todas las demás variedades de la lengua tuvieron lugar, ante todo, en la morfología; fueron pocas, pero afectaron aspectos fundamentales del sistema gramatical. Hemos identificado las siguientes:

1. formación de un sistema verbal y nominal de seis personas, tres del singular y tres del plural';

2. escisión del modificador verbal *-ri- ('acción puntual') en dos sufijos homófonos: el reflexivo $-r i^{-1}$ (Imbabura: talirin 'se derrama') y el puntual $-r i^{2}$ (Cotopaxi: puñurini 'dormí un instante', wakarirka 'se puso a llorar'); es de notar que

\footnotetext{
Aunque en rigor el quechua de Imbabura, por lo menos, carece de $3 \mathrm{a}$ p. del plural, pues '(ellos) caminan' no tiene otra expresión posible que purin.
} 
-ri-1 'reflexivo' es mucho más productivo que -ri-2 'puntual' (Muysken 1977: 114);

3. formación de un progresivo $-x u-\sim-k u$ - a partir del orientador actancial $-k^{b} u$ - ('hacia el sujeto') del quechua cuzqueño antiguo (González Holguín [1607] 1975: 111v-112r);

4. pérdida del sufijo verbal interpersonal '

5. reemplazo de las flexiones de persona nominal por herramientas léxicas (por ejemplo, Imbabura: kamba turi 'tu hermano');

6. reemplazo del gerundio no concordante *-pti- por la forma $-k p i \sim-x p i$, amalgama del agentivo $-k \sim-x$ y del locativo $-p i^{3}$;

7. creación de un sufijo -llata 'mismo', procedente de la amalgama de *-lla y *-taq, propio del quechua meridional, como equivalente de 'mismo' en castellano, como en estos ejemplos imbabureños: paypa taytikupa panillata 'la misma hermana de su papá', kaypillatami kapanga 'estará aquí mismo' (Valencia Baño 2018: VII-5 y I: 23).

La mayoría de los cambios anteriormente listados fue inducida o favorecida por el contacto con el español. Ello es claramente perceptible en los casos (1), (4), (5) e, incluso, (7). Aunque a primera vista resulte menos evidente, el castellano suscitó también la segunda de estas innovaciones. En los demás dialectos quechuas, el sufijo modificador verbal - $r i$ - interviene para reducir la acción a su mínima extensión, como en este ejemplo del ayacuchano: asin 'ríe' $\rightarrow$ asirin 'suelta una (son)risita'. Con algunos verbos, adquiere un significado incoativo: pawan 'vuela' $\rightarrow$ pawarin 'emprende vuelo'. Ahora bien, en el quechua septentrional, -ri- ha desarrollado un significado reflexivo: llikirin 'se desgarra' (Imbabura), niringičix '(ustedes) se dicen' (Chimborazo), armaringi 'te bañas' (Cañar). No se observa una continuidad semántica entre los empleos aspectuales de $-r i^{2}$

\footnotetext{
2 Innovación ausente de la variedad periférica del Pastaza peruano y no del todo consumada en algunas hablas de la sierra (Garcés 1997).

3 En la variedad del Pastaza peruano, el gerundio no concordante - kpi sólo subsiste en expresiones fosilizadas, habiendo dejado lugar, en muchos contextos, a estrategias analíticas.
} 
('acción puntual') y los de $-r i^{-1}$ como reflexivo, de modo que parece muy improbable que este último se haya formado de modo puramente endógeno a partir del primero. En cambio, si consideramos los equivalentes de traducción en castellano de los verbos más comúnmente modificados por -ri- en quechua (no solo ecuatoriano), observamos que existe una muy elevada correspondencia entre el uso de -ri-y formas reflexivas en español. He aquí algunos ejemplos:

$\begin{array}{ll}\text { hata-ri- } & \text { 'levantarse' } \\ \text { mancha-ri- } & \text { 'asustarse' } \\ \text { yuya-ri- } & \text { 'acordarse' } \\ \text { kuyu-ri- } & \text { 'moverse' } \\ \text { anchu-ri- } & \text { 'alejarse' } \\ \text { kuši-ri- } & \text { 'alegrarse' } \\ \text { apa-ri- } & \text { 'llevarse' } \\ \text { rikča-ri- } & \text { 'despertarse' }\end{array}$

De esta observación se puede inferir que los hablantes españoles de la "lengua del Inga" - sobre los cuales volveremos-fueron los que interpretaron -ri- como un reflexivo y generalizaron su uso como tal en el momento de la formación del quechua septentrional. Esta innovación implica, en dicha etapa, una discontinuidad de la transmisión lingüística: se creó una distancia estructural entre el significado que el quechuahablante daba a ese morfema y el que le dio el receptor español; el uso que este hizo de la lengua se volvería después modélico para los grupos nativos del Ecuador, cuando estos adquirieron el quechua como segunda lengua.

Creemos que el mismo proceso llevó a que el quechua septentrional hiciera de ${ }^{*}-k^{b} u$ - un sufijo progresivo. El progresivo, en efecto, es un aspecto verbal de gran relevancia en castellano, pero que parece haber tenido poco desarrollo en las variedades prehispánicas del quechua (de hecho, Domingo de Santo Tomás no registra en su Grammatica de 1560 ningún morfema que lo exprese). El desarrollo de los progresivos $-c ̌ k a-\sim-\beta^{3} a-$ en el sur, $-y(k) \bar{a}$ - en el 
centro y $-x u-\sim-k u$ - en el norte podría explicarse por una influencia del español. En quechua sureño actual, el orientador actancial $-k U-$, cognada de $-k^{b} u$ - en la antigua variedad cuzqueña, presenta, además de su uso reflexivo, empleos que expresan orientación hacia el sujeto y que no tienen correspondientes morfológicos en castellano. En estos casos, el equivalente de traducción de un verbo modificado por - $k U$ - en quechua es a menudo el progresivo o alguna forma que exprese duración, como en los siguientes ejemplos procedentes de nuestro corpus cuzqueño: waqakun 'está llorando (apartado de los demás)', samakun 'está descansando (sin interacciones con otros)', tiyakun 'está sentado (aparte del resto)', kusikuni 'estoy contento (dentro de mí)', rikč akun 'está despierto (en su cama)'. Todo sugiere que, en Ecuador, $-k^{b} u$-, al igual que -ri-, experimentó un proceso de reinterpretación a partir del modelo del castellano. Esta reinterpretación parece remontarse al siglo XVI. Diego González Holguín, que elaboró gran parte de su Gramatica en Quito, escribió a propósito de $<\mathrm{ccv}$ con dos $\mathrm{cc}>$ (no registra $*<\mathrm{cu}>$ ): "Yten (ccu) significa estarse haziendo lo que dize el verbo aunque no sea en si, ni en su prouecho, como. Tiyani, sentarse. Tiyaccuni, estarse sentado. Micuni, comer. Micuccuni, estarse comiendo" ([1607] 1975: 111v-112r).

Por otra parte, es revelador que una de las pocas innovaciones lexicales del quechua septentrional sea la creación de un verbo 'tener' mediante el lexema čari-: ača alpata čarin 'tiene muchas tierras' (Imbabura). Este verbo procede del quechua central, donde tiene el significado de 'coger, agarrar, tener en las manos'. Es muy probable que su evolución hacia la expresión de la posesión se deba a bilingües castellano-quechua

Lo anterior demuestra que la nitidez con la que el quechua septentrional se distingue hoy de las otras variedades de la familia lingüística es la consecuencia de su particular contacto con el español. En la última sección de este artículo, volveremos sobre las circunstancias históricas susceptibles de explicar por qué, en Ecuador, los efectos de ese contacto fueron tan profundos. Primero, explicaremos el proceso de convergencia dialectal que precedió la cristalización colonial del quechua septentrional. 


\section{El APORTE CUZQUEÑO}

Alfredo Torero (1964: 465-466) observó que la presencia de oclusivas aspiradas en el quechua septentrional delata en él una influencia superestratística del cuzqueño. También notó que el rasgo glotal cuzqueño está reflejado, en algunas zonas de Ecuador, por un rasgo aspirado o por una fricativa, como en los siguientes ejemplos:

\begin{tabular}{llll}
\hline & cuzqueño antiguo & ecuatoriano \\
\hline 'cansarse' & šayk'u- & $>$ šayxu- (Imbabura) \\
'hoja' & p'anqa & $>p^{h}$ anga (Chimborazo), fanga (Imbabura) \\
'romper' & p'aki- & $>$ phaki- (Chimborazo), faki- (Imbabura) \\
'arena' & t'iyu & $>$ thiyu (Chimborazo) \\
\hline
\end{tabular}

Otro reflejo de la presencia de dicho rasgo en la genealogía del quechua septentrional es, en algunos lexemas, la consonante protética $h$, producto, en el quechua cuzqueño-boliviano, de la glotalización de la primera consonante de palabras iniciadas por una vocal (para una explicación de este fenómeno, véase Mannheim 1990: 144): butku (Cañar, Chimborazo) 'hueco' (< cuz. butk'u< ‘uckku), buku (Cañar) 'húmedo' (< cuz. buq'u< protoquechua *uqu). Estos casos, sin embargo, son pocos: la mayoría de los términos que en quechua cuzqueño adquirieron un rasgo glotal y una $h$ protética no presentan $b$ inicial en los dialectos ecuatorianos, lo que constituye un indicio de que las formas de procedencia cuzqueña en ese conjunto dialectal no son sino préstamos puntuales de parte de una variedad del quechua cuya base es otra, como se verá más abajo.

El aporte cuzqueño al quechua septentrional se manifiesta, asimismo, en el relajamiento articulatorio que afecta las consonantes en posición implosiva en las variedades del centro y el norte de Ecuador. Las fuentes escritas muestran que este cambio - probablemente consecuente a la adquisición de los rasgos glotal y aspirado- ya se había iniciado en la variedad cuzqueña del siglo XVI. Estas son algunas correlaciones entre el cuzqueño moderno y las variedades ecuatorianas: 


\begin{tabular}{|c|c|c|c|c|}
\hline & & protoquechua & cuzqueño actual & quechua septentrional \\
\hline$* / \mathrm{p} /$ & 'beber' & *upya- & [uюуa-] & $\begin{array}{l}\text { ubya- (Cañar), } \\
\text { ufya- (Imbabura) }\end{array}$ \\
\hline$* / \hat{\mathrm{c}} /$ & 'cerrar' & "wiĉqa- & [wısq'a] & $\begin{array}{l}\text { wička- (Cañar), } \\
\text { wiška- (Chimborazo) }\end{array}$ \\
\hline$* \mathrm{k} /$ & 'barrriga' & *wiksa & [wixsa] & $\begin{array}{l}\text { wiksa (Cañar), } \\
\text { wixsa (Chimborazo) }\end{array}$ \\
\hline$* / K /$ & 'plata' & *quKqi & [qulqu] & $\begin{array}{l}\text { kuKki(Cañar), } \\
\text { kulki(Imbabura) }\end{array}$ \\
\hline
\end{tabular}

Como se observa en este cuadro, el sur (Cañar) presenta formas más conservadoras que el centro y el norte. Ello puede tener varias explicaciones. Una de ellas podría responder a un grado menor de influencia superestratística del cuzqueño en el quechua cañari, pero también podría reflejar una diferencia cronológica en la incorporación de estas zonas al dominio inca. Sabemos, por las fuentes históricas, que la región de Quito se integró al imperio entre fines del siglo XV y principios del siglo XVI. En cambio, según dataciones radiocarbónicas recientes, la presencia inca en el sur de Ecuador se remonta a mediados del siglo XV o tal vez un poco antes (Ogburn 2012: 231). En esos años, el proceso de debilitamiento de las consonantes sílabo-finales en cuzqueño no habría estado tan avanzado como 50 años después.

La morfología del quechua septentrional presenta, asimismo, varios elementos que, fuera de ese grupo dialectal, solo aparecen en el área cuzqueño-boliviana. Ya señalamos el origen cuzqueño de la forma $-x u$ - del progresivo ecuatoriano. El tematizador interrogativo -ri (Chimborazo, pitax yačarkari? ‘ ‘quién sabía?’) también es, fuera de Ecuador, un morfema exclusivo del cuzqueño-boliviano (y de la franja oriental del ayacuchano). En expresiones fosilizadas del quechua septentrional aparecen el sufijo intensificador -ymana del cuzqueño antiguo (Cañar, Napo: sumaymana 'bellísimo') y el verbalizador -Ki- 'poner': čumbiরi- 'ponerse la faja' (Cañar, Chimborazo, ingano), que tiene el mismo origen. 
Finalmente, el léxico del quechua septentrional comprende unidades propiamente cuzqueñas o cuzqueño-bolivianas, como ušuši uši 'hija de varón' (< cuz. ant. ušuši), kačun xačcun 'nuera' (< cuz. q'ačun), Kuki 'izquierda' (< cuz. Kuq'i), pakari- 'amanecer' (< cuz. paqari-), kuyči 'arco iris' (< cuz. k'uyči), turu 'barro' (< cuz. t'uru), etc.

\section{BASE NORPERUANA DEL QUECHUA ECUATORIANO-COLOMBIANO}

Si la impronta del cuzqueño antiguo se manifiesta sobre todo en los niveles fónico y léxico, a nivel morfológico, el quechua septentrional muestra un claro parentesco con las variedades norperuanas. Con respecto a la mayoría de los demás dialectos quechuas, la morfología verbal del ecuatoriano-colombiano ha pasado por un proceso de simplificación drástica: los sufijos modificadores verbales, que son 23 en la actual variedad surperuana de Andahuaylas, son 9 en la variedad de Cañar (Howard 1981: 19-21). Los dialectos del norte de Ecuador presentan un inventario morfológico equivalente, con algunas creaciones propias, como el honorífico -pa- (Taylor 1982). Ahora bien, esta simplificación morfológica caracteriza también las variedades del norte del Perú y debemos considerarla como una herencia norperuana en el quechua ecuatoriano y no como una innovación de este último. En efecto, el quechua de Ferreñafe redujo a diez sus modificadores verbales, dejando un inventario en gran parte coincidente con el del quechua ecuatoriano. A partir de los estudios de Taylor (1996) y Howard (1981), hemos establecido la siguiente lista comparativa de los sufijos modificadores verbales del ferreñafano y del quechua de Cañar:

\begin{tabular}{llll}
\hline & Ferreñafe & Cañar \\
\hline hacia el sujeto & $-k u-$ & progresivo & $-k u-$ \\
translocativo & $-m u-$ & translocativo & $-m u-$ \\
recíproco & $-n a k u-$ & recíproco & $-n a k u-$ \\
\hline
\end{tabular}




\begin{tabular}{llll}
\hline & Ferreñafe & & Cañar \\
\hline \multirow{2}{*}{ factitivo } & & reflexivo & $-r i-$ \\
& $-\check{c} i-$ & factitivo & $-\check{c} i-$ \\
resultativo & $-r a-$ & resultativo & $-r a-$ \\
& & estativo & - raya- \\
inminencial & $-n a-$ & inminencial & $-n a y a-$ \\
iterativo & $-p a-$ & & \\
& & prospectivo & $-g r i-$ \\
progresivo & $-y a-$ & & \\
pasivo-reflexivo & $-k a-$ & & \\
simultáneo & $-s k i-$ & & \\
\hline
\end{tabular}

No incluimos en el cuadro anterior el incoativo -ri, común al ferreñafano y al quechua cañari, pues en ambas variedades solo subsiste en estado lexicalizado. Como se observa, de los nueve modificadores verbales del quechua de Cañar, tres constituyen creaciones del quechua septentrional en cuanto a significado (el progresivo $-k u$ - y el reflexivo $-r i$-), o significado y forma (el futuro cercano - gri-); cuatro son compartidos en cuanto a forma y significado con el quechua de Ferreñafe; y dos (el estativo -raya- y el inminencial -naya-) se pueden interpretar como préstamos del quechua cuzqueño. La forma conservadora-naya- del inminencial parece haber reemplazado la forma evolucionada -na- del ferreñafano $(<-n \bar{a}-$ del QI), que tiene el mismo significado, mientras que el préstamo -raya- ha venido a formar un doblete con la forma heredada $-r a-(<-r \bar{a}-$ del QI), con los significados respectivos de 'acción insistente' y 'acción duradera incumplida' (Howard 1981: 20). El progresivo norperuano - ya- no se ha transmitido al quechua septentrional (o desapareció de él), como tampoco el pasivoreflexivo - $k a-$ ni el simultáneo -ski-, probablemente debido a su baja frecuencia en ferreñafano. En cuanto a su morfología verbal, podríamos decir que el quechua cañari es una variante a la vez 
simplificada y cuzqueñizada del ferreñafano o, en realidad, de los dialectos norperuanos en general, ya que el inventario morfológico de estos es relativamente unitario.

Existen otros indicios de la procedencia norperuana del quechua septentrional. El ferreñafano presenta una innovación que prefigura uno de los cambios definitorios de la variedad ecuatoriano-colombiana: el reemplazo del gerundio no-concordante - $p t i$ - por la forma $-x p i$. Encontramos en efecto en ferreñafano una serie de adverbios de tiempo o de lugar que combinan el agentivo $-q$ y el locativo $-p i$ de modo casi gramaticalizado: tutaparaqpi 'en la oscuridad' (lit. 'en lo que es de noche'), limpu acbkiyaqpi 'al amanecer' (lit. 'en lo que la oscuridad se ilumina'), yatan kaqpi 'cerca de él' (lit. 'en lo que es su cercanía'), nan riqpi 'en el camino' (lit. 'en lo que anda el camino'), etc. Hasta donde hemos podido averiguar, el quechua cajamarquino no presenta este tipo de adverbios, con excepción de los pocos que existen también en otras variedades, como tutayaqpi ('en la oscuridad').

Asimismo, el honorífico-pa-, que contituye un desarrollo de las variedades del centro y el norte de Ecuador, parece tener su antecedente en el quechua de Ferreñafe (Taylor 1996: 36).

El quechua ecuatoriano comparte con las variedades de Cajamarca, Ferreñafe y Chachapoyas otra innovación fundamental en su sistema gramatical: el sufijo $-m i$ ha dejado de ser un evidencial constativo (por lo menos en el quichua de la sierra), para conservar solamente su función enfática; esta evolución aparece más nítidamente en el ferreñafano, geográficamente más cercano al ecuatoriano, que en el cajamarquino (Quesada 1976: 157; Taylor 1996: 52; 2000: 87; 2005a: 103).

Por razones de espacio, no trataremos aquí la dimensión lexical de la cuestión. Bastará señalar que, en una muy alta proporción, los lexemas quechuas que distinguen el QII septentrional de su pariente cuzqueño se encuentran también en norperuano y en quechua central, lo que apoya la tesis de una filiación norperuana del ecuatoriano-colombiano: 


$\begin{array}{ll}\text { norperuano y ecuatoriano } & \\ \text { aswa } & \text { 'chicha' } \\ \text { čusku } & \text { 'cuatro' } \\ k a m z ̌ a & \text { 'maiz tostado' } \\ k a s ̌ a & \text { 'espina' } \\ q u n u q \text { (Ferreñafe) rkunuk (Ecuador) } & \text { 'tibio' } \\ \text { ruku } & \text { 'anciano' } \\ \text { tamya } & \text { 'lluvia' } \\ \text { uqša (Ferreñafe) ukša uxša (Ecuador) } & \text { 'ichu' }\end{array}$

Finalmente, un rasgo relaciona al quechua septentrional, tanto con los dialectos norperuanos como con el cuzqueño antiguo: la sonorización alofónica de las oclusivas posnasales. Las formas pungu 'puerta' (/punku/), pamba 'lugar plano' (/panpa/), randi'comprar' (/ranti/) son comunes a las variedades de Ferreñafe y de Imbabura, por ejemplo, y también existían en el quechua cuzqueño tal como hablaban los incas (Itier 2013). No nos parece aventurado pensar que la sonorización posnasal en las variedades norperuanas y ecuatoriano-colombianas forma parte del aporte superestratístico del quechua de los incas a ambos conjuntos dialectales.

Los elementos anteriores demuestran que la base dialectal del quechua ecuatoriano fue el quechua norperuano y no una fantasmática variedad costeña. Gerald Taylor (1990: 44) ya había esbozado esta hipótesis, aunque sin desarrollarla de modo demostrativo.

Probablemente, el quechua ya desaparecido de la serranía de Piura fue una continuación del ferreñafano constituyendo un puente entre los dialectos "mixtos" septentrionales y los — predominantemente QII- del Ecuador. Rasgos fonéticos y léxicos apoyan la hipótesis de esta conexión aunque un desarrollo específico local y fenómenos de superestrato expliquen parte de las divergencias actuales entre el ecuatoriano y los dialectos considerados aquí.

En conclusión, el quechua norperuano se propagó hacia Ecuador en un contexto de intenso contacto con el cuzqueño, dando lugar a un proceso de koinetización, como lo señaló Pieter Muysken (2019: 
19), lo cual también se produjo en el norte del Perú, aunque con un menor impacto del cuzqueño. Reconstruiremos ahora el marco histórico de dicho proceso.

\section{El PROCESO HISTÓRICO DE KOINETIZACIÓN DEL QUECHUA EN ECUADOR}

Torero no encontró más apoyo histórico para su hipótesis que la Historia del reino de Quito de Juan de Velazco (1727-1792), según la cual, entre el año 980 y la conquista inca, habría existido en la región de Quito un "reino de los Scyris”, en el que se hablaba quechua y cuyos fundadores habían llegado por el mar (1974: 73-74). En un trabajo desafortunadamente ignorado por Torero, Jacinto Jijón y Caamaño ([1952] 1997: 42-44) demostró que la Historia de Velazco fue una "superchería nacionalista" y un conjunto de "patrañas" de las que nada se podía rescatar. En cambio, como veremos, las verdaderas fuentes, es decir, las que recogen el testimonio de los andinos del siglo XVI, son numerosas y unánimes en señalar a los incas como los primeros introductores del quechua en los Andes septentrionales.

La documentación muestra que la sección del corredor interandino comprendida entre Loja y Carangui fue colonizada de modo masivo por grupos llevados por los incas desde el actual territorio peruano. La implantación de estos mitimaes fue especialmente importante en Riobamba, Latacunga, Quito y Carangui (Oberem 1998: 152; Bray 2018: 695), una zona que presentaba condiciones geográficas parecidas a las de los valles cuzqueños.

Entre los "peruanos" que se asentaron en mayor número en los Andes septentrionales figuran los huayacundos de la sierra de Piura, que ayudaron a Huayna Cápac en la conquista de los Caranguis, en la actual provincia de Imbabura, y que por ello fueron premiados con tierras en todo el corredor interandino de Ecuador (Espinoza Soriano 1975, 2006). Los huayacundos fueron especialmente numerosos en Quito y sus alrededores, donde ejercieron un importante papel de dirección política (Espinoza Soriano 2006: 93), 
aunque también establecieron colonias en Latacunga, Chimbo y Cañar (2006: 67). Las fuentes del siglo XVI muestran que la antroponimia huayacundo era en gran parte quechua y coincidente con la del centro-norte del Perú ${ }^{4}$. Ello sugiere que, desde una época sin duda muy anterior al Tahuantinsuyo, dicho grupo practicaba una variedad de quechua próxima al ancashino. El desarrollo del gerundio no-concordante - xpi en Ecuador podría verse como un indicio indirecto del rol de los huayacundos en la quechuización de Ecuador, pues hemos visto que esta forma tiene su antecedente directo en la serie de adverbios desarrollados por el quechua de la sierra de Ferreñafe, una zona inmediatamente contigua, hacia el sur, al territorio de los huayacundos.

Otro grupo particularmente favorecido por los incas fue el de los chachapoyas. Muy aguerridos, opusieron una resistencia tenaz a los cuzqueños, antes de unirse a ellos para la conquista de nuevos territorios, al igual que los huayacundos y los cañares. El rol de las colonias chachapoyas para el control inca de la zona de Quito fue clave (Salomon 1986: 160). Los huambos, oriundos de la actual provincia peruana de Chota, al norte de Cajamarca, también eran numerosos en Quito (Espinoza Soriano 2006: 79) y en Chimbo (Espinoza Soriano 1983-85: 171). Grupos cajamarcas se asentaron en la región de Quito (Espinoza Soriano 2006: 79) y en la provincia de Chimbo (Espinoza Soriano 1983-85: 171; Ponce Leiva 1991: 297). Como se observa en la "Relación de los repartimientos, indios y encomenderos que hay en el corregimiento de Chimbo", de 1577 (Ponce Leiva 1991: 284), la antroponimia de las élites cajamarcas era muy semejante a la que figura en las fuentes sobre las provincias de Huaylas y Cajatambo, lo que sugiere que ellos también manejaban

El padre de Diego de Figueroa Caxamarca, cacique de los mitimaes guayacundos de Quito a mediados del siglo XVI, se llamaba Carhuatanta (Hocquenghem 1990: 45, 46), un nombre netamente centroperuano. El curaca de los mitimaes huayacundos de Chapacoto, un asentamiento multiétnico en la región de Chimbo, se llamaba Simón Carguatocas (1990: 65), otro apellido frecuente en el centro del Perú. Hoy en día, la toponimia no hispana de la sierra de Piura es esencialmente quechua (1990: 49). Un documento señala que estos mitimaes hablaban todos "la lengua guayacunda que es la del inga” (Hartmann 1994: 109). 
inicialmente un quechua de tipo norcentral. Asimismo, en la zona de Quito y en la provincia de Chimbo se establecieron huamachucos, cuyo territorio original se situaba al sureste de Cajamarca (respectivamente Espinoza Soriano 2006: 79; 1983-85: 171). Quito y Chimbo acogieron también grupos procedentes de la provincia de huaylas (2006: 79, 81, 82) .

Los huayacundos y los chachapoyas, así como probablemente los huambos, los cajamarcas, los huamachucos y los huaylas, fueron fuerzas no pacificadas que se pusieron al servicio del Estado inca en expansión y fueron retribuidas con tierras. Podemos pensar incluso que su adhesión al imperio fue motivada por el proyecto de conquista de "las provincias de Quito", como las llaman las fuentes, es decir el centro y el norte del actual Ecuador. Quizá debamos incluir en estos grupos mercenarios a los cañaris, habitantes de un espacio que las fuentes del siglo XVI no incluyen entre las mencionadas provincias. De hecho, junto con los chachapoyas, fueron hasta la época colonial temprana los más fieles aliados de los incas del Cuzco.

Después del norte del Perú, Cuzco fue la segunda región de origen de los colonos "peruanos" en "Ecuador”, particularmente en Quito (Espinoza Soriano 1983-85 y 2006: 79; Oberem 1998: 152). Era común, además, que caciques incas administraran asentamientos de mitimaes multiétnicos, como se observa en Azancoto (Ponce Leiva 1991: 285). Los grupos oriundos de otras regiones del Tahuantinsuyo eran mucho menos numerosos, tal vez por razones de adaptación geográfica o de distancia. En la zona de Quito, encontramos sin embargo angaraes, huancas y yauyos (Salomon 1986: 163), así como lupacas (Espinoza Soriano 2006: 79), un grupo que tuvo una alianza militar temprana y estrecha con los incas. Según la "Relación del pueblo de San Andrés de Xunxi, provincia de Riobamba” (1582), una colonia de condesuyos —otro grupo políticamente próximo a los incas- estaba establecida en la

\footnotetext{
5 Para más detalles sobre la colonización norperuana de la mitad norte de Ecuador, véase Hartmann 1994.
} 
provincia de los puruhaes (Ponce Leiva 1991: 321). Este panorama colonizador explica la configuración dialectal que presentamos en las primeras secciones de este artículo: quienes introdujeron el quechua en Ecuador fueron, en primer lugar, grupos oriundos del norte del Perú, que operaron en estrecha colaboración con colonos cuzqueños y, secundariamente, algunos otros aliados de estos.

En un párrafo breve, pero iluminador sobre el origen del quechua ecuatoriano, Rodolfo Cerrón-Palomino (1987: 344) ya había esbozado este guion, aunque sin renunciar a la tesis toreriana del "quechuismo preincaico" del Ecuador. Asimismo, Roswith Hartmann (1994) destacó el rol de los mitimaes norperuanos, en particular de los huayacundos, en la colonización de dicho territorio, observando incluso semejanzas entre las variedades ecuatoriana y norperuana, pero ella tampoco se atrevió a sacar todas las conclusiones que imponían las fuentes históricas.

El impacto cultural del imperio inca sobre "las provincias de Quito" fue mayor que en cualquier otra parte del Tahuantinsuyo. Refiriéndose a sus habitantes, Cieza de León, que recorrió los Andes en 1547, señala que "[e]n todas partes adoraban al Sol [y] tomavan las costumbres de los Yngas tanto que pareçía que avían naçido todos en el Cuzco" (Cieza [1553] 1996: 164). Bajo el dominio inca, la población de los Andes septentrionales modificó sus formas de vestir - manifestación de un profundo cambio cultural-, abandonando sus tradicionales mantas de algodón por uncus y anacos de tipo "peruano" (Oberem 1998: 160). Este proceso de imitación, suscitado por lo atractivo de la economía política cuzqueña, debió ser el que indujo la "cuzqueñización” del quechua difundido por los mitimaes norperuanos. Cieza de León ([1553] 1996: 165) percibió esa aspiración de integración a la esfera inca de parte de los grupos nativos del actual Ecuador: «Entendían en aprender la lengua general del Cuzco y en saber las leyes que avían de guardar”. Una relación de 1582 también hace eco del prestigio del quechua entre los puruhaes, quienes tenían incluso la lengua "general del Inga” "por más pulida” que la suya propia (Ponce Leiva 1991: 321). 
Las fuentes señalan que los agentes de la transmisión del quechua a las poblaciones locales fueron los mitimaes "peruanos". En Peleusí, en la provincia de Cañar, el Inca instaló un grupo de colonos cuzqueños entre cuyas funciones estaba la de transmitir la lengua común a la población local:

[en Peleusí] hablan la dicha lengua de los cañares entre ellos y la conversan; pero todos saben y hablan la lengua del Inga general, y entre nosotros y otras gentes tratan y conversan con la dicha lengua; porque dicen que el Inga expresamente les mandaba que la hablasen y para ello pobló por aquí gente del Cuzco [...] de los cuales deprendieron la lengua general con que ahora se tratan entre nosotros ("Relación [...] de esta ciudad de Cuenca y de toda su provincia" (1582), en Ponce Leiva 1991: 386).

En Quito, los huayacundos desempeñaron una importante función de transmisores culturales (Salomon 1986: 162-163), lo que sin duda implicó una dimensión lingüística. La documentación no es precisa en cuanto a las circunstancias exactas en las que se realizaba esa transmisión. Es probable que las poblaciones locales adquirieran la lengua participando en las faenas estatales y aprendiendo nuevas técnicas en los diversos campos de la producción, entre los cuales se encuentra la textilería lanar que los incas promovieron con éxito en Ecuador (Oberem 1998: 160). Sea lo que fuere, todo sugiere que, en las “provincias de Quito", los incas tuvieron una política de quechuización mucho más afirmada que en las regiones del imperio donde preexistían lenguas vehiculares como el aimara o el quingnam.

Esta política tuvo éxito. Diversas fuentes señalan el difundido bilingüismo de los cañaris (Cieza de León [1553] 1995: 142, cap. XLIII; "Relación [...] de esta ciudad de Cuenca y de toda su provincia” (1582), en Ponce Leiva, t. I, 1991: 374, 382, 386, 401, 404). La lengua del Inga también estaba muy difundida entre los puruhuaes, vecinos norteños de los cañares ("Relación del pueblo de San Andrés de Xunxi, provincia de Riobamba” (1582), en Ponce Leiva 1991: 321). Según Cieza ([1553] 1995: 141, cap. XLIII), 
los habitantes de las faldas del Tungurahua, al este de Riobamba, "hablan la lengua general del Cuzco: aunque tenían y tienen las suyas particulares" (véase también [1553] 1995: 132, cap. XLI). En 1582, un poco al norte de Otavalo, «[1]a lengua que hablan los indios de este pueblo [Caguasqui] y Quilca, es la que se trata en esta comarca de Otavalo, particular, aunque la mayor parte de todos estos indios hablan la general del Inga; y puesto caso que algunos no la hablan, entiéndenla muy bien" ("Relación [...] de la doctrina y pueblo de Caguasqui y Quilca” (1582), en Ponce Leiva 1991: 416).

La situación lingüística cambiaba radicalmente alrededor de la actual frontera entre Ecuador y Colombia, precisamente donde la presencia de cerámica inca se vuelve nula o muy escasa (Meyers 1998: 224). La provincia de los pastos, hoy perteneciente al segundo de estos países, fue la más septentrional del imperio inca, aunque de muy reciente incorporación. En 1572, el quechua no estaba muy difundido en ella, si exceptuamos algunos yanaconas llevados desde Quito por los conquistadores españoles ("Relación del opispado de Quito” (1572), en Ponce Leiva, t. I, 1991: 214). El quechua tampoco se implantó en la costa de Guayaquil, donde los incas no ejercieron su dominación, de modo que el español pronto se impuso allí como el idioma común ("Descripción de la ciudad de Guayaquil” (1605), en Ponce Leiva, t. II, 1992: 18, 34). Asimismo, el quechua estaba casi ausente de la vertiente occidental y tropical de la sierra norte del actual Ecuador ("Relación [...] de lo que en este pueblo de Lita hay" (1582), en Ponce Leiva, t. I, 1991: 415). Existe una total coincidencia entre el área de implantación del quechua en los Andes septentrionales y las regiones bajo control inca.

\section{RETRACCIÓN Y REMODELACIÓN DEL QUECHUA EN EL SIGLO XVI}

Otras fuentes parecen contradecir este panorama de amplia difusión del quechua en el Ecuador del siglo XVI. Según el jesuita Blas Valera, que escribió antes de 1590: 
muchas provincias, que cuando los españoles entraron en Cassamarca, sabían esta lengua común los demás indios, ahora la tienen olvidada del todo, porque, acabándose el mundo y el Imperio de los Incas, no hubo quien se acordase de cosa tan acomodada y necesaria para la predicación del Santo Evangelio, por el mucho olvido que causaron las guerras que entre los españoles se levantaron, y después de ellas por otras causas [...]. Por lo cual, todo el término de la ciudad de Trujillo y otras muchas provincias de la jurisdicción de Quito ignoran del todo la lengua general que hablaban (en Garcilaso [1609] 1976: 90, lib. VII, cap. III).

Un observador español advierte en 1568 que "en 40 leguas [= ca. 200 o $250 \mathrm{~km}$ ] alrededor desta ciudad [Quito] ay mas de veinte diversidades de lenguas e muchos destos indios no entienden la lengua general destos reynos" (Hartmann 1979: 275). Lo corrobora una relación anónima de 1582 relativa al valle de los Chillos, muy cerca de la capital de la Audiencia: "Después que el ynga los conquisto an hablado la lengua general del dicho ynga y agora hablan las lenguas que quieren y saben y ban totalmente olvidando la general del dicho ynga" (Caillavet 1988: 532). En 1623, una visita realizada en la región de Quito tuvo que recurrir a un intérprete que hablaba la "lengua materna".

A fines del siglo XVI, el conocimiento del quechua en la Audiencia se había vuelto tan insuficiente que el Sínodo Diocesano de Quito, reunido en 1594, juzgó necesario mandar traducir el catecismo y el confesionario a varios idiomas del obispado: el cañar, el puruai, el pasto y el quillacinga, además de algunas lenguas "de los llanos", encargando nominalmente la traducción a reconocidos expertos en estas lenguas (Jijón y Caamaño [1952] 1997: 70). Ignoramos si esta tarea se cumplió, pero varias lenguas maternas del corredor interandino mantuvieron su vitalidad hasta mucho después. Todavía a fines del siglo XVII, se practicaba el idioma local en una provincia

\footnotetext{
6 "As late as 1623 a visita covering places all over the inter-Andean Quito basin made auxiliary use of a lengua materna still unknown to us. There are sufficient grounds to accept a hypothesis of Quichua as used everywhere, but not by everybody or at all times” (Salomon 1986: 173).
} 
tan próxima a Quito como la de Cayambe, pues, en 1685, el “auto de la Numeración de los indios” de dicha provincia se realizó tanto en quechua como en lengua materna” (Ramón Valarezo 1987: 223). En la misma época, una "Carta de órdenes del Presidente de la Real Audiencia de Quito" del 25 de noviembre de 1692 ordena "que en Puruaes donde ni la lengua general del Inca se habla en la mayor parte se habla la materna, se ha de poner mayor trabajo, aplicación, con castigo para que hablen la española" (citado por Jijón y Caamaño 1997: 70) ${ }^{7}$.

¿Cómo interpretar estas divergencias entre las fuentes? Creemos que los testimonios de Blas Valera y del anónimo autor de la relación del valle de los Chillos (1582), según los cuales el uso del quechua retrocedió durante la segunda mitad del siglo XVI, deben tomarse en serio, como lo piensa también Chantal Caillavet (1988: 529). Nuestra hipótesis es que, después de la conquista, el quechua se replegó hacia los centros de colonización española hasta el punto de que la Iglesia lo hallara insuficiente para cumplir con su labor en las doctrinas rurales. Es probable que el retroceso aún no fuese perceptible cuando Cieza de León recorrió la región a principios de 1547. Los corregidores que cuatro décadas más tarde subrayaron la amplia difusión del quechua señalan, en realidad, que dicha lengua solo es comprendida de modo pasivo por un amplio sector de la población. Esta comprensión, probablemente obtenida en circunstancias de movilización laboral y de intercambios comerciales, no fue juzgada por la Iglesia suficiente para el adoctrinamiento.

En cambio, sabemos que en las ciudades el uso del quechua se mantuvo como una necesidad absoluta para la comunicación entre españoles e indígenas hablantes de una multitud de idiomas. Esta debió ser incluso la principal función de la "lengua del Inga" en los siglos XVI y XVII. A ello se refería, para la zona de Peleusí,

\footnotetext{
7 La fecha de 1629 que aparece en dicha página debe ser un error, pues el mismo Jijón y Caamaño ([1952] 1997: 82) parece referirse al mismo documento con la fecha de 1692. M. Hartmann (1979: 273) también da para esta carta la fecha de 1692 y señala que obedece a una cédula real de 1685 . De hecho, esta agresiva política de imposición del castellano pertenece más al contexto de fines del siglo XVII que al primer tercio del mismo siglo.
} 
la observación ya citada de un corregidor a propósito de la "gente del Cuzco [...] de los cuales deprendieron la lengua general con que abora se tratan entre nosotros" (las cursivas son nuestras). Lo confirma una carta dirigida al rey en 1635 por el arzobispo de Quito, quien señala que “en esta ciudad [...] y demás lugares de esa provincia son innumerables los indios que hay de servicio en las casas particulares, a los cuales sus amos y amas los hablan en la lengua del Inca” (Solano 1991: 153-154). A mediados del siglo XVIII, todos los criollos de Quito tenían todavía el quechua como primera lengua (Juan y Ulloa 1826: 377).

Como consecuencia de la prolongada vitalidad de las "lenguas maternas” de Ecuador, excepcional dentro del panorama del virreinato, el quechua tuvo durante mucho tiempo por principal función la de servir para la comunicación entre indígenas y españoles. El hecho de que gran parte de los intercambios lingüísticos en quechua se dieran entre estas dos categorías de personas es la probable explicación de la profunda impronta gramatical que los hablantes españoles del quechua, es decir, los criollos, dejaron en esta lengua en el momento en que iba constituyéndose en idioma vehicular de un nuevo espacio regional, la Audiencia de Quito.

\section{Segunda expansión del Quechua en el siglo XVIII}

Antes de fines del siglo XVIII, el panorama lingüístico de la sierra ecuatoriana había cambiado por completo, pues las lenguas vernaculares estaban todas extintas a favor del quechua. En 1775, el jesuita Bernardo Recio observa el resultado de ese reciente proceso de sustitución lingüística: "Esta lengua quichua es la lengua general y se ha como sorbido las otras lenguas de particulares provincias, ha llevado tras sí otras muchas lenguas y las ha abolido" (1947: 413-414). Ello contribuiría a explicar el florecimiento de descripciones del quechua septentrional y de textos catequísticos en dicha variedad durante el siglo XVIII, mientras que, para el siglo anterior, no conocemos más documentos de ese tipo que la Breve declaración del Arte y Bocabulario de la lengua del Ynga conforme al estilo 
$y$ vso de la provincia de Quito, del jesuita riobambino Hernando

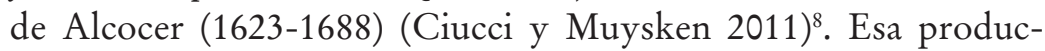
ción reflejaría el advenimiento de una nueva situación en la que el quechua se había vuelto mucho más funcional para la catequización.

¿Qué es lo que llevó a tan drástica transformación del panorama lingüístico de la Audiencia de Quito? A partir de fines del siglo XVI, se inicia en todo el corredor interandino un proceso de captación de la tierra de parte de los hacendados, que se acelera después de 1640 y logra cumplir sus principales propósitos hacia fines del siglo XVII (Ramón Valarezo 1987). Para 1685, en la provincia de Cayambe, los hacendados habían logrado adscribir a sus predios el 78,01\% de la población indígena (1987: 177). Quedaba un 20\% de población libre, que, sin embargo, hacía sus mitas en las haciendas (1987: 177, 200). La situación no era en todas partes tan extrema como en Cayambe. Los otavalos lograron mantener mejor el control del valle interandino (Ramón Valarezo 1987: 105). Pero, de modo general, la hacienda absorbió una enorme proporción de la población indígena. En 1804-05, el 46\% de los tributarios de Ibarra, Otavalo, Guaranda, Riobamba, Alausi y Loja vivían en haciendas y obrajes (1987: 217). Ello fue la consecuencia de una acentuación de la migración indígena hacia la esfera española, que se produjo a fines del siglo XVII y dejó las reducciones toledanas colapsadas (Vieira Powers 2009: 79).

Ese proceso de feudalización, mucho más avanzado que en el resto del virreinato, debió implicar importantes interacciones directas entre indígenas y criollos, consolidando la impronta del castellano sobre el quechua. De hecho, el quechua ecuatoriano manifiesta en su constitución interna, en particular morfosintáctica, el papel central que desempeñaron los criollos bilingües en su propagación entre la población nativa. Todo sugiere, pues, que la segunda expansión del quechua en Ecuador, la del siglo

\footnotetext{
Sabine Dedenbach-Salazar Sáenz (1993) atribuye al siglo XVII el anónimo Arte de la lengua Jeneral de Cusco llamada Quichua, con argumentos que no convencen. El estado de la lengua que describe es más cercano al de mediados del siglo XVIII que al que registra Alcocer.
} 
XVIII, fue la consecuencia de una "reconstitución étnica al interior de la hacienda, [que] arranca de una extrema fragmentación, de un mosaico de indios locales y forasteros que provienen de diferentes ayllos y regiones, que hablan distintas lenguas maternas, que tienen experiencias culturales diversas, pero que logran hacer de la hacienda su espacio de encuentro" (Ramón Valarezo 1987: 230). De este proceso emergió el quechua que describen las fuentes del siglo XVIII y que presenta ya casi todas las características modernas de la variedad ecuatoriana. Esta convivencia entre criollos e indígenas en espacios fragmentados explica también la existencia en Ecuador de un continuo lingüístico entre los dialectos del quichua y el castellano andino, a través de la media lengua (Gómez Rendón 2005: 41). Es una configuración desconocida en Perú y Bolivia, donde la esfera indígena mantuvo gran parte de su autonomía, por lo menos hasta el último tercio del siglo XIX.

\section{Conclusión}

Creemos haber mostrado aquí que la mayoría de los rasgos que definen el quechua ecuatoriano-colombiano como un conjunto dialectal específico consisten en correspondencias morfológicas con el español: la reconfiguración del sistema de las personas verbales y personales; la reinterpretación de los sufijos modificadores verbales $-x u-\sim-k u-$ y $-r i-$ como un progresivo y un reflexivo, respectivamente; el abandono del sufijo verbal interpersonal ${ }^{*}$-šnnki $(3 \rightarrow 2)$ en beneficio de una estrategia analítica; el reemplazo de las flexiones de persona nominal por herramientas léxicas. Este fenómeno de equiparación semántica explica también la formación de un verbo 'tener', en quechua septentrional, a partir de čari-, que originalmente significa, en las variedades centrales, 'tener entre las manos, agarrar'. Aunque no dispongamos de testimonios escritos para demostrarlo, es muy probable que estas innovaciones se hayan originado en el habla de los criollos quechuahablantes de la Audiencia de Quito, antes de difundirse entre la población indígena. Esta difusión debió ser facilitada por el hecho de que, hasta fines del siglo XVII por lo 
menos, el quichua seguía siendo una lengua segunda para gran parte de la población nativa. Sea lo que fuere, el hecho de que la mayoría de las innovaciones definitorias del quechua septentrional se deba al contacto con el español demuestra que el proceso histórico-lingüístico que condujo a la formación del clado ecuatoriano-colombiano del quechua es posterior a la conquista española. No podemos seguir asumiendo, como se hacía desde los estudios de Torero, que el quechua septentrional es una ramificación primaria del protoquechua II, que habría brotado, en una época remota, en la costa central o surcentral del Perú. La tesis de una implantación preincaica del quechua en el Ecuador no tiene fundamentos.

Como se ha visto, todo sugiere, más bien, que los incas fueron quienes introdujeron el quechua en los Andes septentrionales, en gran parte a través de colonos de distintas regiones del Perú. En sus inicios, el quechua debió presentarse en Ecuador como un conjunto de variedades en proceso de "cuzqueñización” y koinetización. Entre ellas, predominaban las del norte del Perú. Sobre ellas, el quechua cuzqueño, tal como lo hablaban los incas, actuó como un superestrato de particular impacto en los ámbitos fonológico y léxico, mientras que la morfología del futuro quechua ecuatorianocolombiano permaneció próxima a su raíz norperuana.

Este es un guion todavía muy general y múltiples preguntas quedan por responder. Habrá que establecer la cronología de las innovaciones que caracterizan el quichua septentrional y relacionarla con los procesos histórico-sociales que las condicionaron. Un trabajo histórico más afinado que el nuestro permitiría sin duda reconstruir con mayor precisión los espacios sociocomunicativos en que los españoles bilingües estuvieron en contacto con la población indígena, así como las diferencias que pudieron existir en ese aspecto de una región a otra. Una historia social del quechua en Ecuador queda pendiente en gran parte. También, nos falta entender en términos históricos la oposición dialectal existente entre la sierra sur y la sierra centro-norte de dicho espacio. Desde un punto de vista externo, la relación especial que une el quechua cañari con el ferreñafano deberá profundizarse y explicarse. 
El tema tratado en este artículo puede tomarse como una ilustración del principal problema que plantea la clasificación genética de los dialectos quechuas que Alfredo Torero propuso en 1964. Torero no tomó en consideración la posibilidad de convergencias dialectales como la que hemos descrito. El modelo filogenético que adoptó para reconstruir la historia antigua del quechua postula que, a partir de una protolengua, se produce una ramificación creciente que excluye fusiones entre ramas distintas. Sabemos, sin embargo, que, a diferencia de las especies animales, los dialectos e, incluso, las lenguas sí pueden converger y hasta fusionarse. Es lo que sucedió en el caso del quechua norperuano, producto del encuentro de una variedad originalmente próxima al ancashino y de un superestrato cuzqueño, como lo demostró Taylor (1996: 6, 32; 2005b). Creemos ilusorio, por lo tanto, clasificar genéticamente las variedades norperuanas dentro de una de las dos ramas primarias del quechua (QI y QII). La misma observación se puede extender al quechua ecuatoriano-colombiano, que combina en su formación elementos lingüísticos de origen cuzqueño y centroperuano. Creemos haber mostrado en trabajos anteriores que un proceso de koinetización se encuentra igualmente en la génesis de la variedad ayacuchana (Itier 2016) e, incluso, aunque en menor medida, del cuzqueño moderno (Itier 2013). La clasificación dialectal de Alfredo Torero, por consiguiente, debe repensarse en profundidad'.

\section{REFERENCIAS BIBLIOGRÁFICAS}

AdelaAr, Willem F. H.

2013 "Quechua I y Quechua II: En defensa de una distinción establecida”. Revista Brasileira de Lingüística Antropológica. 5, 1, 45-65. Consultado: 19 de agosto de 2021. https://doi. org/10.26512/rbla.v5i1.16542.

9 Véase al respecto el reciente debate entre Adrian J. Pearce y Paul Heggarty (2011), y Willem Adelaar (2013). 
BRAY, Tamara L.

2018 "Al final del Tahuantinsuyu: avances imperiales en la frontera norte”. En El imperio inka. Ed., Izumi Shimada. Lima: Pontificia Universidad Católica del Perú.

Caillavet, Chantal

1988 "Una Relación Geográfica inédita de 1582 sobre Ecuador: Oyumbicho y Amaguaña del valle de los Chillos”. Revista Andina. 6, 2, 525-536.

Cerrón-Palomino, Rodolfo

1987 Lingüistica quechua. Cuzco: Centro de Estudios Rurales Andinos "Bartolomé de las Casas".

Cieza de León, Pedro

[1553] 1995 Crónica del Perú. Primera parte. Lima: Pontificia Universidad Católica del Perú - Academia Nacional de Historia.

Cieza de León, Pedro

[1553] 1996 Crónica del Perú. Segunda parte. Lima: Pontificia Universidad Católica del Perú - Academia Nacional de Historia.

Ciucci, Luca y Pieter C. Muysken

2011 "Hernando de Alcocer y la Breve declaración del Arte y Bocabulario de la lengua del Ynga conforme al estilo y vso de la provincia de Quito. El más antiguo manuscrito de quichua del Ecuador”. Indiana 28, 359-393.

Dedenbach-Salazar Säenz, Sabine

1993 Una Gramática Colonial del Quichua del Ecuador. Transcripción e interpretación de un manuscrito del Archivo Histörico Nacional de Colombia. Bonn - St. Andrews: Bonner Amerikanistische Studien 20.

ESPINOZA SORIANO, Waldemar

1975 "Los mitmas huayacuntu en Quito o guarniciones para la represión armada, siglos XV y XVI”. Revista del Museo Nacional. XLI, 351-394.

ESPINOZA SORIANO, Waldemar

1983-85 "La etnia chimbo al oeste de Riobamba: el testimonio de la etnohistoria”. Revista del Museo Nacional. XLVII, 145-257. 
ESPINOZA SORIANO, Waldemar

2006 La etnia Guayacundo en Ayabaca, Huancabamba y Caxas (siglos $X V-X V I)$. Lima: Instituto de Ciencias y Humanidades - Fondo Editorial del Pedagógico San Marcos.

GARCÉs, Fernando

1997 "Sufijos nominales de persona en el quichua ecuatoriano". Lexis. XXI, 1, 85-106.

Garcilaso de la Vega, Inca

[1609] 1976 Comentarios reales de los Incas. Prólogo, edición y cronología de Aurelio Miró Quesada, 2 tomos. Caracas: Biblioteca Ayacucho.

Gómez Rendón, Jorge

2005 "La media lengua de Imbabura". En Encuentros y conflictos. Bilingüismo y contacto de lenguas en el mundo andino. Eds., Hella Olbertz y Pieter Muysken. Madrid - Frankfurt: Iberoamericana - Vervuert.

GÓmEZ RENDÓn, Jorge

2017 "Las lenguas barbacoanas meridionales y el quechua”. Revista Pucará. 28, 55-97. <https://www.academia.edu/30403925/ J_A_G\%C3\%B3mez_Rend\%C3\%B3n_2017_Las_lenguas_barbacoanas_meridionales_y_el_quechua_Revista_ Pucar\%C3\%A1_28_pp_55_97>.

GonzÁlez Holguín, Diego

[1607] 1975 Gramatica y arte nveva de la lengva general de todo el Peru, llamada lengua Qquichua, o lengua del Inca. Vaduz-Georgetown: Cabildo.

Hartmann, Roswith

1979 “QQuechuismo preincaico en el Ecuador?”. Ibero-Amerikanisches Archiv: Zeitschrift des Ibero-Amerikanischen Forschungs-Instituts der Universität Bonn. 5, 3, 267-299.

Hartmann, Roswith

1994 "El papel de los mitimaes en el proceso de quechuización: el caso del Ecuador y la problemática de las fuentes”. América Indígena. 4, 61-98. 
Hocquenghem, Anne-Marie

1990 Los Guayacundos de Caxas y la sierra piurana: Siglos $X V$ y XVI. Lima: Instituto Francés de Estudios Andinos - Centro de Investigación y Promoción del Campesinado. Consultado: 12 de octubre de 2020. <http://www. hocquenghem-anne-marie.com/amh/2_piura_loja/89_amh_ los_guayacundos_de_caxas_y_la_sierra_piurana_siglos_ xv_y_xvi_2.pdf $>$.

Hocquenghem, Anne-Marie

2012 "How did Quechua Reach Ecuador ?”. En Archaeology and Language in the Andes. A Cross-Disciplinary Exploration of Prehistory. Eds., Paul Heggarty y David Beresford-Jones. Oxford - New York: Oxford University Press, 345-371.

Howard-Malverde, Rosaleen

1981 Dioses y diablos, tradición oral de Cañar Ecuador. Textos quichuas recogidos y traducidos por Rosaleen Howard-Malverde. Paris: Association d'Ethnolinguistique Amérindienne.

ITIER, César

2013 "Las bases geográficas de la lengua vehicular del imperio inca". Bulletin de l'Institut Français d'Études Andines. 42, 2, 237260. $<$ https://journals.openedition.org/bifea/8030>.

ITIER, César

2016 "La formación del quechua ayacuchano, un proceso inca y colonial”. Bulletin de l'Institut Français d'Études Andines. 45, 2, 307-326. <https://journals.openedition.org/bifea/8003>.

Jú́N Y CAAMAÑo, Jacinto

[1952] 1997 Antropología prehispánica del Ecuador. Quito: Museo Jacinto Jijón y Caamaño - Embajada de España - Agencia Española de Cooperación Internacional.

JuAn, Jorge y Antonio de UlloA

1826 Noticias secretas de América, 2 vols. London: R. Taylor.

MANNHEIM, Bruce

1990 "La cronología relativa de la lengua y literatura quechua cusqueña”. Revista Andina. 1, 139-177. Consultado: 12 de octubre de 2020. <http://www.revistaandinacbc.com/wpcontent/uploads/2016/ra15/ra-15-1990-06.pdf>. 
Meyers, Albert

1998 Los incas en el Ecuador. Análisis de los restos materiales (I parte). Quito: Abya-Yala - Ediciones del Banco Central de Ecuador. Consultado: 12 de octubre de 2020. <https://digitalrepository. unm.edu/cgi/viewcontent.cgi ?article $=1475 \&$ context=abya_ yala>.

Muysken, Pieter C.

1977 Syntactic Developments in the Verb Phrase of Ecuadorian Quechua. Lisse: The Peter de Ridder Press.

MuYsken, Pieter C.

2019 El kichwa ecuatoriano. Orígenes, riqueza, contacto. Quito: Abya Yala.

Oberem, Udo

1998 "El período incaico en el Ecuador". En Nueva historia del Ecuador, vol. 2. Ed., Enrique Ayala Mora. Quito: Corporación Editora Nacional - Grijalbo, 135-166.

Ogburn, Dennis E.

2012 "Reconceiving the chronology of Inca Imperial Expansion". Radiocarbon. 54, 2, 219-237. https://doi.org/10.2458/azu_js_ rc.v54i2.16014

Parker, Gary J.

[1970] 2013 Trabajos de lingüística bistórica quechua. Ed., Rodolfo Cerrón-Palomino. Lima: Pontificia Universidad Católica del Perú.

Pearce, Adrian J. y Paul Heggarty

2011 "Mining the Data on the Huancayo-Huancavelica Quechua Frontier". En History and Language in the Andes. Ed., Paul Heggarty y Adrian Pearce. Nueva York: Palgrave Macmillan, 87-109.

Ponce Leiva, Pilar (ed.)

1991-1992 Relaciones histórico-geográficas de la audiencia de Quito (siglo $X V I-X I X), 2$ tomos. Madrid: Consejo Superior de la Investigación Científica.

Quesada Castillo, Félix

1976 Gramatica quechua, Cajamarca-Canaris. Lima: Instituto Estudios Peruanos - Ministerio de Educación. 
Recio, Bernardo

[1775] 1947 Compendiosa relación de la cristianidad de Quito. Madrid: Consejo Superior de la Investigación Científica.

Ramón Valarezo, Galo

1987 La resistencia andina. Cayambe 1500-1800. Quito: Centro Andino de Acción Popular. Consultado: 12 de octubre de 2020. <https://biblio.flacsoandes.edu.ec/libros/digital/50743. $\mathrm{pdf}>$.

SALOMON, Frank

1986 Native Lords of Quito in the Age of the Incas. The Political Economy of North Andean Chiefdoms. Cambridge: Cambridge University Press.

SAnTo Tomás, Domingo de

[1560] 1994 Grammatica o arte de la lengua general de los indios de los reynos del Perú. Transliteración y estudio por Rodolfo Cerrón-Palomino. Madrid: Ministerio de Asuntos Exteriores de España - Agencia Española de Cooperación Internacional - UNESCO.

Solano, Francisco de

1991 Documentos sobre política lingüística en Hispanoamérica 1492-1800. Madrid: Consejo Nacional de la Investigación Científica.

TAYLOR, Gerald

1979 Diccionario normalizado y comparativo quechua: Chachapoyas-Lamas. Paris: L'Harmattan.

TAYLOR, Gerald

1982 "Le morphème de respect /-pa-/ dans les parlers quechuas de la sierra équatorienne”. Amerindia. 7, 55-60.

TAYLOR, Gerald

1990 “À la recherche des 'proto-quechua”. Mémoires de la Société de Linguistique de Paris, Nouvelle Série. I, 91-102.

TAYLOR, Gerald

1996 El quechua de Ferreñafe. Fonología, morfología, léxico. Cajamarca: Acku Quinde Asociación Andina. 
TAYLOR, Gerald

2000 Estudios lingüísticos sobre Chachapoyas. Lima: Universidad Nacional de San Marcos - Instituto Francés de Estudios Andinos.

TAYLOR, Gerald

2005a Método de quechua chachapoyano. Lima: Editorial Commentarios.

TAYLOR, Gerald

2005b "Innovaciones morfológicas en un dialecto quechua aislado: el caso de Ferreñafe". En Contribuciones a las vientos. Ed., Sabine Dedenbach-Salazar Sáenz. Aachen: Shaker Verlag, 47-63.

Torero, Alfredo

1964 "Los dialectos quechuas". Anales Científicos de la Universidad Agraria. 2, 446-478.

TORERo, Alfredo

1974 El quechua y la historia social andina. Lima: Universidad Ricardo Palma.

Torero, Alfredo

1984 "El comercio lejano y la difusión del quechua. El caso del Ecuador". Revista Andina. 4, 367-389. Consultado: 12 de octubre de 2020. <http://www.revistaandinacbc.com/wpcontent/uploads/2016/ra04/ra-04-1984-01.pdf>.

TORERo, Alfredo

2002 Idiomas de los Andes. Lingüística e historia. Lima: Instituto Francés de Estudios Andinos.

Valencia Baño, Verónica

2018 "Présentation du répertoire oral d'une conteuse quichua de l’Équateur”. Tesis de Maestría. Institut National des Langues et Civilisations Orientales (París).

Vieira Powers, Karen

2009 Andean Journeys: Migration, Ethnogenesis, and the State in Colonial Quito. Albuquerque: University of New Mexico Press. 